\title{
CORRESPONDENCE
}

\section{Non-English papers decrease rankings}

In applying a set of standard bibliometric indicators to rank the scientific status of 500 universities worldwide for the 2010 Leiden Ranking, we have discovered that the language of publication has a dramatic and largely underestimated effect on citation-based measurements of research performance.

Publications in non-Englishlanguage journals count as part of a country's output, but these generally have a low impact as fewer scientists can read them. This effect is particularly evident in application-oriented fields such as clinical medicine and engineering, and in the social sciences and the humanities.

As clinical medicine represents a considerable part of the scientific output of most nations, the language of publication directly affects the ranking of the university hosting the research (T. N. van Leeuwen et al. Scientometrics 51, 335-346; 2001).

Rankings based on the number of citations per paper and per staff member are responsible for the strikingly low position of many German and French universities, particularly those that include a medical school.

Important ratings by Times Higher Education, QS, the Shanghai Academic Ranking of World Universities and the Leiden Ranking, for example, all unfortunately rely on rankings influenced by this language effect. Ton van Raan, Thed van Leeuwen, Martijn Visser Leiden University, the Netherlands. vanraan@cwts.leidenuniv.nl

\section{Citation bubble about to burst?}

University rankings would be more informative if they took into account graduates' contributions to a country's international economic competitiveness. Although institutes in the United States and the United Kingdom currently top the university rankings, the most successful technologybased export industries are dominated by northern and central Europe, as well as by Asian city states - the per-capita exports of which are also several times higher.

Rankings are heavily influenced by citations, but these represent little more than symbols. They are comparable to the less-than-worthless collateralized debt obligations that drove the recent financial bubble, and, unlike concrete goods and real exports, they are easy to print and inflate.

Financial deregulation led to short-term incentives for bankers and rating agencies to overvalue their collateralized debt obligations, bringing down entire economies. Likewise, today's academic rankings provide an incentive for professors to maximize citation counts instead of scientific progress (by coincidence, both types of incentive were invented in the United States). We may already be in the middle of a citation bubble - witness how relatively unknown scientists can now collect more citations than the most influential founders of their fields.

It may be easier to collect citation indices than employment histories and other statistics about the impact of graduates on industry, but modifying rankings to take these into account would be worth the effort, particularly for institutes and countries that are currently traded below value.

Note that I write from the country with the most citations per capita and per scientist. Jürgen Schmidhuber Istituto Dalle Molle di Studi sull'Intelligenza Artificiale (IDSIA) and University of Lugano, Switzerland.juergen@idsia.ch

\section{Measuring impact of research on society}

We invite scientists to comment on our proposed tool for rating the impact of research publications on society (www.societalimpact.info). We believe that such ratings should eventually be incorporated into assessments of scientific performance.

This tool has been devised by a task force recruited from different disciplines at the Medical University of Vienna (G. Watts Br. Med. J. 338, b553; 2009). It evaluates factors that include the aim of the published investigation; the extent to which authors attempt to translate their scientific findings into societal action; and the level, status and target group of this translation.

Authors' efforts to convey the significance of their results for daily life are particularly relevant. The level of translation (regional, national or international), its status (preliminary or permanent) and its target group (individuals, population subgroups or the public) are other important quantitative indicators.

There will be challenges in implementing our system. Not least is the problem of measuring the likely societal impact of publications from the basic sciences. There will also be an inherent subjectivity in the assessment, and societal rating may not lend itself to computerized calculation. Thomas Niederkrotenthaler, Thomas Dorner, Manfred Maier Medical University of Vienna, Austria. thomas.niederkrotenthaler@ meduniwien.ac.at

\section{How will growing cities eat?}

Food security should not be ignored when assessing the future of our cities (Nature 467, issue 7318; 2010). Urban populations already comprise more than half of humanity and are expanding. This demographic shift will leave fewer farmers to cultivate the food on which cities depend, exacerbating the $20 \%$ decline in the number of farmers over the past 40-50 years.

Food for cities will either have to be sourced from remote locations across the globe, or cities will have to incorporate their own food-production facilities by such developments as peri-urban farming.

A scientific question is how cities and the land areas needed to feed them scale in relation to city population density. Scaling would be expected to be positively nonlinear because of the highly variable biological productivity of terrestrial and marine ecosystems that produce this food. In other words, larger cities will sequester proportionately larger and more marginal, low-productivity areas of land in order to be fed. Local urban and peri-urban food production tends to increase the yield per unit area and may partially counteract this trend.

The nonlinear scaling of food provision with city population size contradicts the idea that cities are proportionately more efficient per inhabitant, with respect to their use of infrastructure, carbon emissions and other services (Nature 467, 912-913; 2010). Food security of dense megacities depends on large, low-population land areas that exist elsewhere and yield disproportionately high food surpluses.

John R. Porter University of Copenhagen, Denmark.

jrp@life.ku.dk

Lisa Deutsch Stockholm

University, Sweden.

David Dumaresq, Rob Dyball Australian National University, Australia. 